\title{
ENGLISH ORATURE, ENGLISH LITERATURE: THE CASE OF CHARMS
}

\section{Jonathan Roper}

Traditional charms are a part of English orature; charms in literature are a part of English literature. This simple distinction does not, however, tell the whole story: charms, as is well known, are sometimes written down, rather than verbalized, in order to function as talismans; charms, no matter how traditionary, can feature motifs more commonly found in literature; and the transmission of charms may involve a written as well as an oral dimension (the most obvious example of this being the existence of spellbooks). On the other hand, charms in literature are not always purely literary: they may have a relationship with traditional verbal charms. At the very least, charms presumably existed in real life before they appeared in literature. This paper, which is not a full survey of charms in English literature, will examine some occurrences of supposed charms in literary texts and compare and contrast these items with the generic characteristics of the genuine article.

For our first example, we can take the University play, Thersites, written in the in 1530 s, probably by Nicholas Udall. This Interlude is a 917-line bit of knockabout which demonstrates "howe that the greatest boesters are not the greatest doers" by showing the comeuppance of the boaster, Thersites. And despite the classicizing names of the characters - Telemachus, Ulysses, and Thersites himself, the continued references to items of contemporary English popular culture throughout the work; e.g. at one stage Thersites says

And we shall make merye
And synge "tyrle on the berye"
With Simkyn Sydnam, somner,
That kylde a catte at Comner.

show that the de facto setting of the action is not in the Ancient Hellenic world. This bodes well for attempts to compare the one charm featured in the play to those current in contemporaneous folk tradition. The charm is spoken by Thersites' mother over his 
former enemy and current friend, Telemachus, to cure him of the worms. After an initial lack of enthusiasm :

Charme that charme wyll; he shal not be charmed of me, Thersites persuades her in to it:

Charme! or, by the masse, with my club I wil charme the!

and she proceeds to utter a charm of fifty-eight 12-syllable lines, mostly in rhyming couplets. The length of these lines and the substantial alliteration in them (sometimes involving as many as five words), mark them off from the typical style of the play, and presumably serve as sign that charms differ from speech. The alliteration is possibly attempting to imitate old popular traditions of versification (perhaps parodically). ${ }^{1}$ However, the charm is no more serious here than the rest of the knockabout in the play: it is a burlesque of a charm. No charmer would ever have referred to "The buttocke of the bytter boughte at Buckyngame" as part of their traditionary magical practice. All the same, even a burlesque charm must still have some kind of relationship to, and must still give some kind of reflection of, notions of the genre it is burlesquing. We need now to briefly describe those generic characteristics.

The fundamental structure underlying charms is bipartite: power is first built up, then it is discharged. So, in the first half of a charm, supernatural personalities tend to be named or addressed, and often a little story (a "historiola") is featured which touches on issues in some way analogous to the plight of the person to be cured, or the object of a charmer's desire. Thus, a blood-staunching charm recorded in nineteenth-century Devon opens with an apocryphal little story of how when Christ was being baptised in the Jordan he struck it with a rod, and it then stood still. In the second half of a charm, the power is discharged, the analogy is cashed in, the magic is worked, often in highly formulaic language. In our Devonshire example, after the initial five lines of the story, the charmer says "And so shall thy blood stand". Another example, is this charm to summon your beloved recorded in 1908 in Somerset:

Water, water, running free,

May my love run swift to me. 
In the first line, water is named, twice, is described performing analogously relevant activity, and in the second line, the desideratum is stated. In the logic of charms, having first named and described something (elemental or supernatural) in the act of running, means that the second line is stronger than if it stood baldly alone.

If we compare the Thersites charm with those recorded from folk tradition, the most immediate structural difference is that it is far longer at 58-lines than the usual length of under a dozen lines. This is because it is in fact eleven charms all in a row, topped off with what we might call a "benediction". But we cannot discount it as an artifice with no links to genuine tradition on this basis alone, any more than our observation that the charm in Thersites is a burlesque, would allow us to dismiss it as being a random illogical nonsense. Whilst real charmers would make reference to St. Anthony, or St. Apollonia, the fact that Thersites' mother makes appeals to "The cowherd of Comertowne with his croked spade" and "jolye Jacke Jumbler, that juggleth with a horne", does not automatically mean that this literary charm is cannot be considered as being charmlike: it still contains invocations, no matter how absurd. What we are looking for is the basic bipartite structure of invoking and discharging power, which would show that though the tenor and the content of these invocations differ from serious examples, the underlying logic, or rhetorical procedure, of charms is being imitated. And indeed there does seem to be a bipartite basis to these eleven charmlets, featuring a first element in which a mythical personality with a relevant attribute is invoked, followed by a second element in which the disease is referred to.

However, these eleven charms (or "sub-charms") are in fact prayers. The bipartite rhetorical structure used here is that of prayer: invocation (e.g. "Our Father who art in Heaven"), followed by request (e.g. "Give us this day"). The first four lines show this invocationrequest pattern very clearly:

The cowherd of Comertowne with his croked spade [invocation] Cause frome the the wormes soone to vade. [request] And jolye Jacke Jumbler, that juggleth with a horne, [invocation] Graunte that thy wormes soone be all to torne. [request] 
And the game is given away completely by the mother's later choice of language, though she is invoking "Mother Bryce of Oxforde and greate Gyb of Hynxey", the language is clearly that of prayer:

Inclyne youre eares and heare this my peticion And graunte this childe of healthe to have fruition.

The blessinge that Jorden to his godsonne gave, Lyghte on my chylde and from the wormes him save.

Listening to charms, we do not hear such supplicatory verbs as "grant", "cause that", "help that". Even if we consider them as more demanding than supplicatory (and prayers can sometimes seem to be nothing more than a list of demands made of God), the rhetoric is not that of charms. The general tone of traditional magical formulae (i.e. those words near the end which are supposed to actually work the magic) is either declarative (for example, "Sinew to sinew and bone to bone" in a charm to heal broken bones, recorded in Exmoor), or it is imperative ("In frost/ Out fire" in a charm to reduce swellings recorded in Somerset as recently as 1957). If the tone is imperative, then it involves commands and adjurations addressed to the offending object (and not to a supernatural source of aid), for example: "Perish, thou tetter, and be thou gone" (in a nineteenth-century charm from Cornwall against "tetter", or ringworm), or to give the example of perhaps the most well-known traditional English verbal charm "Rain, rain, go away."

There is, moreover, one particular trick whereby the adjuration is made by the supernatural source of aid, as instanced, for example, in the following charm, which was found in a Herefordshire charmer's book. It begins with a historiola recounting how Jesus shook upon seeing the cross, then it switches to dialogue:

[---] the Jews asked him, "Art thou afraid or hast thou the ague?" Jesus answered and said "I am not afraid neither have I the evil ague, whoever wears this about them shall not be afraid nor have that evil ague."

The trick of this is that, as recorded in the spellbook, the speechmarks denoting "Jesus's" response include the words "whoever wears this about them shall not be afraid nor have that evil ague", ${ }^{2}$ which means that, rhetorically speaking, it is not the 
charmer who is uttering these words, but the character "Jesus": a crafty way of intensifying the effects of the words. ${ }^{3}$

The Thersites charm exhibits none of these genre characteristics regarding magic formulae, and thus, though it is a delightfully stupid play in itself, and can be used as a secondary source for mediated information on contemporaneous popular culture (for example, it mentions' Mercolfe Movyles', which is a possible reference to the popular anti-hero Mercolf, half a century later than his most famous appearance in the 1492 proverb dialogue Salomon and Marcolphus), and though indeed the treatment of charms may well indicate a university-man's disdain of them, the evidence of the work suggests that its author did not have a deep acquaintance with charm-tradition.

Moving on eighty or so years in time, we find charms in the works of another university-educated man in Ben Jonson's production The Masque Of Queenes. As a prelude to the Masque's celebration of "true fame", Jonson presents, an ante-masque, "a spectacle of strangenesse" in which appears "twelue women, in the habit of hags, or witches, sustayning the persons of ignorance, suspition, credulitie, \&c. the opposites to good Fame".

In fact, this part of the masque involves nine self-styled charms, seemingly rich pickings for a folklorist. But from the start we learn to be wary about the relationship of these charms to those current in contemporaneous folklore when Jonson remarks that while Inigo Jones designed the costumes of those who played the witches, he himself "prescrib'd them their properties of vipers, snakes, bones, herbs, rootes, and other ensignes of their magick, out of the authoritie of ancient and late writers", emphasizing literary points of reference for the piece. And sure enough, the "charms" turn out to be a kind of lyric poetry somewhat reminiscent of Ariel's songs in The Tempest, or of early Yeats:

Dame, Dame, the watch is set:

Quickly come, we all are met.

From the lakes, and from the fens,

From the rocks, and from the dens,

From the woods, and from the caues,

From the church-yards, from the graues, [---] 
and so on. This is decorative poetry: good to sing, and good to set the scene. But it is not like the functional poetry of charms which aims to bring about changes in this world. Jonson's charms are more songs which refer to charms, than charms themselves. It is clear he does understand the purpose and functional nature of charms, as he has one of the hags say:

I went to the Toad breedes vnder the wall, I charm'd him out, and he came at my call;

(which shows a witch performs a charm, and something changes in the world), but he does not begin to succeed in imitating them. This couplet comes shortly before one of Jonson's stage directions/sidenotes in which he describes how in the performance:

Here, the Dame [---] began her following Inuocation; wherein she tooke occasion, to boast all the power attributed to Witches by the Ancients; of which, euery Poet (or the most) doe giue some: Homer to Circe, in the Odyss. Theocritus to Simatha, in Pharmaceutria; Virgil to Alphesiboevs [---]

He then goes on to mention six more classical authors who describe witches.

This is clearly not the place to seek relatively unmediated imitations of English traditional charms.

However, if we seek for traces of verbal charms (or indeed traces of folklore more generally) in contemporaneous drama, then might we be more successful if we consider the works of Jonson's famously non-University-educated friend? In Act Three, Scene Four of Shakespeare's King Lear we find a charm-text with a far greater ring of authenticity:

St. Withold footed thrice the old;

He met the nightmare and her nine-fold;

Bid her alight

And her troth plight,

And aroint thee, witch, aroint thee!

This charm against night-mare (i.e. night-time riding of other people's horses by witches, indicated by finding horses tired in the 
morning), with its historiola and adjuratory formulae, is close enough to folk tradition to persuade the great American historian of witchcraft, George Lyman Kittredge, into believing it is a traditional charm included verbatim in the play. ${ }^{4}$ While I myself doubt in the absence of any independently recorded version of this charm, that it is a genuine slice of folk tradition, one must assume that Shakespeare was acquainted with traditional charms to have been able to have written this. For although the Frenchified aroint strikes a rather false note, ${ }^{5}$ and lines 3 and 4 are unclear in purpose (who are they addressed to? are they the words spoken by Saint Withold to the witch, are they utterance instructions implying the charmer is to wait till the right moment before uttering the final line?), ${ }^{6}$ it certainly has the "feel" of a charm.

It is at the start of Act IV of Macbeth, when the hero encounters the witches for a second time, that we find the most famous spellscene in English literature. However very little of what the witches utter has the logic or rhetoric of a charm to it. The witches make use of three kinds of discourse in this scene. One of these is a general oracular tone used to address Macbeth ("Beware the Thane of Fife. Dismiss me enough"). Another is charm-like discourse, where entities (locks, fires, cauldrons) are invoked and commanded, to give the chief instances: "Open, locks, / Whoever knocks" and "Double, double, toil and trouble;/ Fire burn and cauldron bubble."7 But the predominating mode of discourse in this passage is what we might call that of the pseudo-charm. What I mean is runs such as this:

Fillet of a fenny snake,

In the cauldron boil and bake;

Eye of newt and toe of frog,

Wool of bat and tongue of dog,

Adder's fork and blind-worm's sting,

Lizard's leg and howlet's wing,

For a charm of powerful trouble,

Like a hell-broth boil and bubble.

Pseudo-charm utterance is like that of a charm in its poetical devices: use of rhymed four-beat verse (the most common form for metrical charms), plentiful alliteration (which, though by no means 
as regular as in native Anglo-Saxon and Middle English productions, is perhaps Shakespeare's deliberate choice in representing magical speech to present a relict of ancient English versification), and a tendency toward parataxis (which is, after all, a less obviously sensical device than syntaxis if used for any length). It even selfreferentially makes a claim for its pretended charm-ness in including the word "charm" in the body of the text itself. Pseudo-charm utterance is unlike a charm in its logic or rhetoric. The lines quoted above do not contain the imperative structures, or the analogic historiolas, or the build-ups and releases of power, which are typical of real charms. A couplet such as "Fillet of fenny snake,/ In the cauldron boil and bake" is an instruction the witch is to follow in producing the magic potion. Shakespeare is not a folklorist, presenting the witches speaking a charm, but rather a dramatist conjuring up in his own way the atmosphere of the witches' gathering, artificially, by having his characters speak what they in fact know, and would not need to say. This narratizing break-down of "the ingredients of our cauldron" (similar to Homer's narratizing breakdown of the Shield of Achilles, at least in Lessing's interpretation), serves to set this scene, (sometimes as directly as a narrator would: "Thrice the brindled cat had mew'd./ Thrice and once the hedge-pig whined."), and differentiate the action from the previous palace scene, and at the same time as pretending to be something other than scene-setting and plot-development by using the form of speechact a witch would use to perform magic. We must presume that dramatically this must have been more effective. This observation, when considered together with the examples of Jonson's and Thersites' "charms", gives us to think that it is precisely in drama that literary "charms" are least likely to be charm-like.

If we move on now to the works of a lyric poet, Herrick, we can find several works headed "Charme". We need not disqualify them on that ground alone, for though in the Shakespeare quoted above it was a sure sign that if the body of a text should contain the word "charm" it could not in fact possibly be one, it is far from uncommon to come across written examples of traditional magic (for example, in a charmer's papers or spellbook) which include the word in what must be their emic title, or folkname. However, upon looking beyond the titles, we can see that they are not charm-like: 
A charme, or an allay for Love

If so be a Toad be laid

In a Sheeps-skin newly flaid,

And that ty'd to man 'twil sever

Him and his affections ever.

A second example:

Another Charme for Stables

Hang up Hooks, and Sheers to scare

Hence the Hag, that rides the Mare,

Till they be all over wet,

With the mire, and the sweat:

This observ'd, the Manes shall be

Of your horses, all knot-free.

These are not charms, but instructions for traditional magic, a sort of cross between the rhymed instructive adages of the Tudor farmer Thomas Tusser, and the performance instructions found recorded with the Old English charms in the Lacnunga and the Leechdoms). Indeed, so traditionary is the content of these literary texts that they are used by folklorists as corroboratory evidence for the existence of certain aspects of custom and belief. In the Oxford Dictionary of Superstitions, Iona Opie and Moira Tatem, cite this "charm for stables" to provide the first English record of iron being used to deter evil, a practice which is only later recorded by the antiquaries and folklorists.

But Herrick's lyrics (or in fact the most part of the whole category of lyric poetry) can show us something else as well. Whereas modern day anthologists such as Causley, Heaney and Hughes ${ }^{8}$ include charms (or rather transcriptions of the verbal parts of charm performances) in their pages, (which amounts to a recognition of the poetical qualities of charms, a suggestion that it is acceptable to include charms as a sub-category in the general category of literary texts), and whereas, as we have briefly seen above, English literary authors have both drawn on the traditionary lore instantiated in charm procedures, and have imitated and burlesqued verbal charms in their own literary works, we nevertheless cannot say that there is only one way of thinking hierarchically of these two categories. If we consider Herrick's lyric "To the Genius of his 
house", we can start to realize how poetic invocations are in their own way charms:

Command the Roofe great Genius, and from thence

Into this house powre downe thy influence,

That through each room a golden pipe may run

Of living water by thy Benizon.

Fulfill the Larders, and with strengthning bread

Be evermore these Bynns replenished.

Next, like a Bishop consecrate my ground,

That luckie Fairies here may dance their Round:

And after that, lay downe some silver pence,

The Masters charge and care to recompence.

Charme then the chambers; make the beds for ease,

More then for peevish pining sicknesses.

Fix the foundation fast, and let the Roofe

Grow old with time, but yet keep weather-proofe.

It has the logic of a spell. The command, (the conjuration in fact, for 'to command' in Latin is conjuro), names the (non-human) addressee, and proceeds to command it on what it should do. This is not entirely a jeu d'esprit, Herrick half-believes in the "Great Genius" and more than half means his commands to be realized. (Or so I suppose). It is not just simply the case that magical texts have some of the characteristics of poetry about them: poetry (especially lyric poetry) has some of the characteristics of magic about it. Both lyric poetry and charms (together with not-too-dissimilar forms such as prayers, benedictions, vows and curses) are typically different from conventional utterance in featuring invocations, expressions of wants/desiderata, displaying a sense of an ending/resolution, being highly organized in terms of sound-patterning, rhythmical patterning, parallelisms, redundancy, etc. Did these two categories of expression develop these characteristics independently? If not, which was the borrower (and of what?) from the other? Could poetry then be considered a descendant of, a sub-category of the overarching category charms-and-prayers? Who can say which has the precedence? 


\section{Comments}

${ }^{1}$ Similarly, Shakespeare, in A Midsummernight's Dream, has the Athenian mechanical (ciphers for unsophisticated English people) use (clumsy) alliteration in their verse-making.

${ }^{2}$ Versions of this same charm-type discovered in use in written form as talismans about the necks of dead men in Norfolk and Sussex also share this punctuation.

${ }^{3}$ For a more extended discussion of this particular rhetorical ploy see Edina Bozóky 1992 article.

${ }^{4}$ Kittredge (1929: 219): "for pre-Elizabethan England one must not forget the fine old epic charm preserved in King Lear."

${ }^{5}$ S. H. writing in the Gentleman's Magazine (1784, Vol. 54: 73) mentions that the Rowan (or "Witchen") tree was considered protection against witchcraft interprets the phrase "Aroint thee, witch" (this time in Macbeth I: iii) as representing "A Rauntree, witch!" Perhaps this belief was part of Shakespeare's native folklore, or perhaps he found it in (or was reminded of it by) a passage in James the First's Daemonologie "Charmes as commonlie dafte wiues vses [---] for preseruing them [cattle] from euill eyes, by knitting roun-trees [---] to the haire or tailes of the goodes [cattle]."

${ }^{6}$ If it is the case that these lines are utterance instructions then Shakespeare's familiarity with charms may result from his reading of them in contemporary literature on magic (which he certainly referred to for the names of demons mentioned in this Act of the play), in which case, lines 3 and 4 of this charm would represent the transcription error of Shakespeare the folklorist.

7 There is also the charm-like rhyme referred to as "a song: 'Black spirits,' \&c.", which is not always used in productions, but is possibly reconstructable from Middleton's play The Witch as: "Black spirits and white, red spirits and grey,/ Mingle, mingle, mingle, you that mingle may." This raises a string of questions such as is this rhyme Shakespearian or traditional? Presumably it is traditional, if it is referred to by its opening and is found in another playwright's work. If it is traditional, then what genre of thing is it? A charm? A song (as it is described in the directions)? Was presented with any melody or a specific one? Where charms generally still sung at this period (as they were in Saxon times)? If so, did the charm-melodies have a specific typology (e.g. descending melodic contours, pentatonism etc?) distinct from other "secular" music? 
${ }^{8}$ The Penguin Book of Magical Verse and The Rattle Bag are two modern anthologies which along with more traditionally literary texts include charms sub speciae poesis. This is part of a broader appropriation by literature and its representatives of primarily functional or sacred verbal forms. For some the previous high-water-mark of this movement was the postwar publication The Bible as Literature.

\section{References}

Bozóky, Edina 1992. Mythic Mediation in Healing Incantations. Campbell, S., Hall, B., Klausner, P. (eds.). Health, Disease and Healing in Medieval Culture. London: Macmillan, pp. 84-92.

Kittredge, George Lyman 1929. Witchcraft in Old and New England. New York: Russell and Russell. 